\title{
Valor-notícia nas rádios comunitárias
}

\section{News values in the community radios}

Dioclécio Ferreira da Luz I dioclecioluz@terra.com.br Jornalista e mestre em Comunicação pela Universidade de Brasília (UnB), pesquisa radiojornalismo nas rádios comunitárias e tem nove livros publicados, abordando meio ambiente, cultura,

literatura e comunicação.

\section{Resumo}

Os critérios de noticiabilidade - ou valores-notícia - das rádios comunitárias devem se submeter aos seus princípios. Servir à comunidade é o principal deles. Como o radiojornalismo nessas emissoras deve ser aberto à comunidade e elaborado por voluntários, ele tenderia a se diferenciar dos demais veículos. Igualmente, também os valores-notícias que estas emissoras adotam seriam singulares.

Palavras-Chave: Rádios comunitárias; Valor-notícia; Radiojornalismo

\begin{abstract}
The criteria of newsworthiness - or news values - of the community radio stations must respect their principles; serving the community as the main one. Since radio journalism at these stations should be opened to the community and prepared by volunteers, it would tend to differ from other communication vehicles. Likewise, the news values that community radio stations adopt would be differentiated.
\end{abstract}

Keywords: Community radio; News values; Radio journalism 


\section{Radiojornalismo em rádios comunitárias}

A questão do valor-notícia nas emissoras comunitárias, propósito deste artigo, fez parte da pesquisa que concluímos em janeiro de 2011, necessária para obtenção do título de mestrado no Programa de Pós-Graduação da Faculdade de Comunicação da Universidade de Brasília. A pesquisa teve um caráter mais abrangente que este artigo - ela abordou os conceitos e práticas do radiojornalismo nas rádios comunitárias $(\mathrm{RC})$ e não somente a questão do valor-notícia.

O trabalho consistiu num cotejamento de informaçóes entre os que fazem rádio comunitária "na prática" com as concepções teóricas esboçadas por estudiosos do tema. Visitamos oito rádios comunitárias e entrevistamos pessoalmente seus dirigentes e/ou responsáveis pelo jornalismo; entrevistamos "autoridades no assunto" (dirigentes de outras emissoras, militantes, estudiosos, pesquisadores acadêmicos e não acadêmicos); averiguamos a bibliografia de referência sobre o assunto.

O objetivo da pesquisa era estabelecer um quadro de práticas e conceitos de radiojornalismo nas RCs que representasse todo o país. Decidimos selecionar e pesquisar um grupo de "emissoras-padrão", aquelas RCs diferenciadas entre si que possuíam determinadas características de programação e gestão. Formou-se um grupo heterogêneo de oito emissoras-padrão, distribuídas por três regiôes. Estivemos no Nordeste, na Rádio Sol e Rádio Guabiraba (Pernambuco), na Santa Luz FM e Valente FM (Bahia); no Sudeste, na Rádio Heliópolis (São Paulo); no Centro-Oeste, na Rádio Utopia, Nova Vida e Líder FM (Distrito Federal).

Foram visitadas emissoras autorizadas (reconhecidas pelo Estado) e não autorizadas. Ter ou não autorização pouco importava para a pesquisa. Mais importante era saber qual a concepção do dirigente para o radiojornalismo nas condiçóes em que a emissora se encontrava (sujeita ou não à repressão pelo Estado). O grupo incluiu emissoras que fazem radiojornalismo: a) rotineiramente, b) esporadicamente, ou c) que planejam fazer no futuro.

A pesquisa concluiu que não há - hoje - um radiojornalismo que seja característico das rádios comunitárias. Ao que parece ele está em formação. No entanto, alguns conceitos e práticas são visíveis em algumas emissoras ou na concepção de dirigentes, estudiosos ou militantes.

Eis os conceitos e práticas que a pesquisa identificou: a notícia como "um processo" (ela não se esgota na fala do locutor); o ouvinte faz a notícia; a linguagem é informal; o radiojornalismo prioriza o local (a comunidade); o radiojornalismo tem compromisso com a comunidade; a notícia é um serviço de caráter social; o radiojornalismo depende da credibilidade; o radiojornalismo necessita de liberdade para atuar; o valor-notícia é focado na comunidade; a prestação de serviços é parte do radiojornalismo; o formato radiojornalismo é adequado à RC; as principais fontes de notícia estão na comunidade; propaganda não deve ser confundida com jornalismo; o tempo do jornalismo é dado pela notícia.

\section{A notícia}

Vamos considerar "notícia" como a divulgação, difusão ou relato de fatos ou acontecimentos por meio da comunicação. 
Luiz Costa Pereira Junior observa que "a notícia resulta de seleçôes e exclusões deliberadas nestes três momentos do trabalho com a informação: apuração, apresentação (redação, produção de imagens) e edição" (PEREIRA JUNIOR, 2010, p. 55).

É função do jornalista selecionar, entre tantos acontecimentos, o que é notícia. É preciso ter critérios para fazer essa seleção, saber identificar os valores-notícia ou "critérios de noticiabilidade", assim definidos por Traquina:

Os critérios de noticiabilidade são o conjunto de valores-notícia que determinam se um acontecimento, ou assunto, é susceptivel de ser notícia, isto é, de ser julgado como merecedor de ser transformado em matéria noticiável e, por isso, possuindo "valornoticia" (newsworthiness). (TRAQUINA, 2005, p. 63).

Esses critérios de noticiabilidade não são fixos no tempo ou no espaço. O que é valor-notícia pode mudar com o tempo e de acordo com o veículo de comunicação. Para os jornais populares, por exemplo, assassinato é um valor-notícia poderoso; para uma rádio comunitária este tipo de acontecimento pode não merecer atenção e até ser descartado.

Não é muito claro para os repórteres ou editores quais os critérios que utilizam para identificar e selecionar o que interessa para o jornalismo. Traquina (2005, p. 62) diz que diversos estudos revelam que os jornalistas têm "uma enorme dificuldade" em explicar o que é notícia e deixar claro quais são os seus critérios de noticiabilidade. Marcelo Parada, que atua em rádio comercial, diz que, em geral, os jornalistas são movidos pelo "faro" na escolha do que é notícia.

No caso das rádios comunitárias, nossa pesquisa observou um problema de origem: o radiojornalismo comunitário é feito por voluntários, não jornalistas em sua grande maioria, e estes desconhecem as técnicas básicas de jornalismo. Mas a prática do radiojornalismo que lhes daria esse "faro", essa percepção “indescritível” para o que é notícia. E, embora possamos rastrear alguns elementos, identificar alguns valores-notícia recorrentes, o elemento subjetividade sempre vai estar presente.

De qualquer modo, como diz Nelson Traquina, identificar o que é notícia não parece ter lastro científico:

À pergunta "o que é notícia?” podemos responder que a resposta dos membros da tribo jornalística não é cientifica, aparece como instintiva, e permanece quase como uma lógica não explicitada. [...] Não há regras que indiquem que critérios têm prioridade sobre os outros; mas os critérios de noticiabilidade existem, e são duradouros ao longo dos séculos. (TRAQUINA, 2005, p. 96, grifo nosso).

Apesar dessa visão, existem algumas regras e critérios mínimos para selecionar o que é notícia. Considere-se o que diz Luís Mauro Sá Martino: para alguns jornalistas a seleção é um processo racional. No entanto,

se para o jornalista parece evidente quais são os critérios de seleção, a análise das matérias publicadas mostra não apenas a escolha arbitrária, mas também certas regularidades 
no tratamento da informaçấo que indicavam a existência de categorias subjetivas para a seleção dos fatos. (MARTINO, L. M., 2003, p. 109).

Para Luís Mauro Sá Martino, cada fato teria um “preço simbólico” que mostraria sua potencialidade de ser transformado em notícia.

Já Ciro Marcondes Filho associa o valor-notícia ao clichê. Ele diz que o valor-notícia resulta da busca de clichês pelos jornalistas. A maior parte das notícias se estruturaria em torno de clichês. "Assim eles (os jornalistas) se tornam atores privilegiados na manutenção de idéias, verdadeiros agentes conservadores da cultura” (MARCONDES FILHO, 2002, p. 109). Operar com clichês, segundo o mesmo autor, é mais fácil, mais simples. Clichês constroem as notícias: “jornalistas não partem para o mundo para conhecê-lo; ao contrário, eles têm seus modelos na cabeça e saem pelo mundo para reconhecê-los (e reforçá-los)" (idem).

O jornalismo, portanto, teria uma função conservadora. Os jornalistas, ainda segundo Marcondes Filho, reconstroem diariamente o mundo com o objetivo de "manter o mundo exatamente como ele é, a saber, o mais próximo da fantasia que as pessoas têm do mundo" (MARCONDES FILHO, 2002, p. 120).

O primeiro estudo sobre o valor-notícia foi feito por David White, em 1950. Ele observou o processo de gatekeeper nas redaçóes - como se seleciona o que é e o que não é notícia. Suas conclusões quanto ao processo nas redações apontam, também, para escolhas subjetivas.

Nelson Traquina (2005) sistematizou as concepçóes de diversos autores sobre valor-notícia, incluindo a sua também:

a) Para Mitchel Stephens (1988) as "qualidades duradouras" das notícias são: o extraordinário, o insólito, o atual, a figura proeminente, o ilegal, as guerras, a calamidade e a morte.

b) Herbert Gans (1979), estudando os telejornais das três principais cadeias norte-americanas (ABC, CBS e NBC) e as revistas Newsweek e Time, em épocas diferentes, concluiu que $85 \%$ das notícias sobre assuntos nacionais tratavam de pessoas conhecidas: 1) o presidente dos Estados Unidos; 2) ministros e a família do presidente; 3) pessoas conhecidas envolvidas em escândalos.

O que era notícia? 1) conflitos e desacordos dentro do Governo; 2) decisões e propostas do Governo e cerimônias; 3) mudanças de pessoas. O estudo ainda aponta para três categorias de acontecimentos: os protestos, os desastres e o insólito.

c) Gantung e Ruge (1965/1993) teriam sido os pioneiros nos estudos para identificaçáo dos valores-notícia adotados pelos jornalistas. Ao final enumeraram 12 valores-notícia: 1) duração do acontecimento; 2) a amplitude do evento; 3) a clareza ou falta de ambiguidade; 4) a significância; 5) a consonância (facilidade de inserir o "novo" numa velha ideia que corresponda ao que se espera); 6) o inesperado; 7) a continuidade (da notícia); 8 ) a composição (em relação às demais notícias); 9) a referência às naçôes de elite; 10) a referência às pessoas da elite; 12) a referência às pessoas envolvidas; 12) negatividade (bad news is good news).

d) Ericson Baranek e Chan identificam como valor notícia: 1) a continuidade; 2) a consonância; 3) o inesperado (os acontecimentos negativos 
“parecem ter mais valor-notícia”); 4) a infração (de leis, a má gestão, mau comportamento de funcionário ou autoridade).

e) Nelson Traquina concebe:

e.1 - valores-notícia de seleção:

e.1.1 - por critérios substantivos (avaliação da notícia por sua importância): a morte ("onde há morte há jornalistas"), a notoriedade, a proximidade, a relevância, a novidade, o tempo, a notabilidade (a qualidade de ser visível, tangível) ${ }^{1}$, o inesperado, o conflito ou a controvérsia, a infração, o escândalo.

e.1.2 - por critérios contextuais (contexto de produçáa): disponibilidade (condiçóes de fazer a cobertura), equilíbrio (em relação ao que já foi dado, ou se foi dado em quantidade), visualidade (para a TV, se tem imagens; para o rádio, se há som, registro sonoro ou relato etc.), a concorrência (a questáo da disputa, o "furo"), o dia noticioso (um evento pode ser derrubado pelo outro).

e. 2 - valores-notícia de construção: a simplificação (fatos complexos, intraduzíveis, perdem para os mais claros), a amplificação (o título amplia a dimensão do fato e faz virar notícia), a relevância (para a sociedade, para o Governo etc.), a personalização (quanto mais personalizado o acontecimento mais chances tem a notícia de ser notada), a dramatização (reforço ao emocional), a consonância.

O jornalista José Cleves trata os valores-notícia como temas de "interesse jornalístico". Quais são eles?

Interesse público: é o que mexe com o bolso, com o destino, com a qualidade de vida do cidadão, despertando o interesse coletivo por questóes como o patrimônio, propriedades e variaçôes no custo de vida; as inquietaçóes políticas de maior relevância; o clima de insegurança; os prejuízos aos cofres públicos ou qualquer medida política de maior impacto no orçamento e no futuro da população, em suas necessidades básicas.

Interesse popular: é aquele motivado pela curiosidade, o probabilístico, o bizarro, o entretenimento e a crença.

Interesse privado: $\mathrm{o}$ interesse individual, particular, de alguma pessoa ou instituição - ou grupos destas, por questóes imateriais acerca de um determinado fato que não interessa à coletividade.

Interesse transitório: acontecimentos que interessam ao público naquele momento ou naquele período (eventos sazonais, de épocas bem definidas pelas estaçóes do ano ou eventuais pela sua natureza, porém de relativo interesse jornalístico).

Interesse volátil: os de grande emoção, fugazes como os prazeres do esporte e da competição. (CLEVES, 2009, p. 172).

\section{Valor-notícia para o rádio}

A princípio não há diferença entre o valor-notícia adotado para diferentes veículos. O que é notícia para o jornal impresso também seria para o rádio ou 
para TV. Mas não é assim. Na TV - onde o que mais importa é a imagem - essa diferença é bem mais evidente. A imagem "graciosa" de um gatinho mamando o peito de uma cadela pode render a matéria final do telejornal de sábado. Essa mesma notícia, conforme um dos critérios contextuais apresentados por Traquina ("visualidade"), provavelmente não seria veiculada numa emissora de rádio. Também podemos cogitar de matéria sobre fotos revelando atos irregulares de autoridades públicas - teria bom espaço no jornal impresso, mas sofreria limitaçôes no rádio.

A definição do valor-notícia para cada veículo não é somente uma questão de suporte tecnológico. As particularidades de cada um definem o jornalismo e, antes disso, o que é valor-notícia para cada um. O imediatismo do rádio pode descartar matérias sobre eventos do passado. $\mathrm{O}$ jornal impresso pode desprezar a fala de determinada pessoa se a matéria (o fato jornalístico) depender do tom de quem fala (raivoso, irônico, brincalhão) e, assim, impossibilite sua transcrição no jornal.

Andrew Boyd, citado por Marcelo Parada, lista o que seriam "os elementos das grandes notícias" para o radiojornalismo (PARADA, 2000, p. 24):

1) Proximidade - A notícia precisa falar de algo que seja de interesse do ouvinte.

2) Relevância - O acontecimento deve ser do interesse do maior número de pessoas.

3) Imediatismo - A força do rádio é relatar o que está acontecendo aqui e agora.

4) Interesse - Somar o que a audiência precisa saber com o que ela quer saber é acertar. "Errar na dose é fatal", porém.

5) Drama - "Perigo, aventura, conflitos, perseguiçôes, crimes, rendem grandes notícias".

6) Entretenimento - Sendo também "companhia para o ouvinte”, o rádio não pode ser somente "sério". O ouvinte sempre estaria em busca de:

- Hora certa

- Emergências

- Denúncias

- Atos de governo

- Conflitos e debates

- Saúde

- Reclamaçóes de ouvintes

- Dá para resolver

- Previsão do tempo

- Esportes 
- Trânsito e estradas. (PARADA, 2000, p. 24):

E se o assunto não se encaixa em nenhum dos acima citados, Parada sugere um "teste final" para decidir se ele é notícia ou não: verificar se se encaixa em um dos seguintes tópicos (PARADA, 2000, p. 27):

- Importante

- Trágico

- Raro

- O último ou o mais recente

- O mais caro

- Acabou de acontecer

- Vai acontecer

- O primeiro ou o maior.

\section{Valor-notícia na comunitária}

Definir o que é notícia para o radiojornalismo comunitário requer o desenvolvimento de uma "sensibilidade" com relação ao veículo e, principalmente, um olhar diferenciado sobre a comunidade. É o olhar do repórter-parceiro da comunidade. É o repórter que vê o que poucos vêem, e decide: "isto é notícia"; é o olhar do morador que percebe e avisa: "a rádio comunitária precisa denunciar isso"; ou, "a rádio precisa fazer alguma coisa em relação a isso". Estas decisões nem sempre são objetivas - nem sempre se sabe o porquê da seleção. Na dúvida apelam para a regra geral: tal fato é notícia porque é importante para comunidade.

Edisvânio Nascimento, responsável pelo jornalismo na rádio comunitária Santa Luz FM (município de Santa Luz, Bahia), diz que o valor-notícia está no local: "notícia é focar nas causas do município, da nossa cidade, da nossa comunidade" 2 .

A nossa pesquisa sobre radiojornalismo em rádios comunitárias (citada anteriormente) permitiu sistematizar três valores-notícia para essas emissoras:

1. Problemas na oferta de serviços públicos: transporte, educação, saúde, saneamento etc. Denúncias e/ou cobranças de correção. Estradas esburacadas, falta de água, escolas que não têm professores, ônibus que não cumprem horário;

2. Denúncias de irregularidades no serviço público. Autoridades envolvidas em corrupção; corruptos e corruptores etc.; e

3. Solidariedade. Ajuda aos desempregados, inválidos, doentes etc. Procura de emprego; orientação sobre como ter acesso aos benefícios do Estado; localização de desaparecidos... Em alguns casos este valor-notícia se confunde com assistencialismo. 
Em nossa opinião também é notícia para o radiojornalismo comunitário aquilo que:

1. Aconteceu na comunidade

2. É de interesse da maioria

3. Tem a ver com o cotidiano da comunidade

4. É uma ação do povo organizado

5. É uma ação do homem comum

6. Promove a educação

7. Promove a arte e cultura local

8. Promove a integração da comunidade

9. Aconteceu no Brasil e diz respeito a todos

10. Estimula a criatividade, a cultura e a beleza.

Andrés Geerts, da Associación Latinoamericana de Educación Radiofónica (ALER), diz que na rádio "queremos escutar":

- o que se passa em nossos campos e nossos bairros,

- o que sofremos e também o que gozamos,

- o que nos fazem e também o que fazemos,

- nossa vida, nossa cultura, nossas organizaçóes,

- nosso ponto de vista sobre o que é nosso e o alheio,

- e como quiséramos que fosse este mundo ingrato. (GEERTS, 1993, p. 9, tradução nossa).

O mesmo autor detalha quais seriam os três principais critérios para selecionar notícias em uma rádio popular ou comunitária: "1) o que interessa à nossa audiência saber; 2) a conjuntura política em que se vive; 3) o que todo mundo anda comentando" (GEERTS, 1992, p. 35, tradução nossa).

Finalmente, Geerts orienta sobre quais devem ser as "preferências" da $\mathrm{RC}$ sobre o que noticiar:

1) preferimos o que afeta a muitos mais do que o que afeta a poucos (os novos preços do leite, pão e arroz, aos novos preços dos cosméticos importados);

2) preferimos o que é de interesse dos pobres mais do que é de interesse dos poderosos (as eleiçóes dos sindicatos às eleições do Rotary Club);

3) preferimos o que se passa mais perto da nossa audiência do que o que se passa distante (uma marcha de protesto no bairro mais que uma marcha na China);

4) preferimos as ações do povo organizado mais do que o que faz um indivíduo, por mais famoso que seja (a construçáo de uma estrada vicinal à última canção de Madonna); 
5) preferimos o atual mais que o passado (a guerra contra o tráfico de drogas às guerras de independência do passado);

6) preferimos o que se passa em nossos países mais do que o que se passa nos países ricos (a seca no Nordeste brasileiro à atmosfera contaminada de Nova York);

7) preferimos o de cada dia, o que é comum, mais que o excepcional ou extraordinário (a fome nos campos mais que a aparição de um disco voador). (GEERTS, 1992, p. 36, tradução nossa)

Para José López Vigil (1997, p. 239), são cinco os valores-notícia de uma rádio comunitária:

\section{a) A proximidade da notícia com a audiência.}

Uma proximidade que é expressa em três coordenadas: 1) temporal (atualidade); 2) proximidade ("o mais próximo se converte no mais noticiável”); 3) o interesse particular da audiência ("a proximidade de interesse é o indicador de rota, caminho aberto e não túnel”). O autor alerta, porém, para a necessidade de contextualização histórica das notícias: "a atualidade sem história resulta de uma irresponsável amnésia jornalística, faz caótico o mundo" (LÓPEZ VIGIL, 1997, p. 240, tradução nossa).

\section{b) $\mathrm{O}$ raro, o insólito, o extraordinário.}

"Destacar o que sai do normal não implica necessariamente sensacionalismo ou superficialidade" (LÓPEZ VIGIL, 1997, p. 242).

\section{c) $\mathrm{O}$ trágico, o desastroso, o catastrófico.}

Para López Vigil, calamidade não é somente terremoto ou enchentes. Grandes problemas sociais são tragédias que devem ser noticiadas. A rádio deve noticiar que quase 1 bilhão de pessoas passa fome no mundo; que há milhóes de crianças morando nas ruas; que milhôes de pessoas estão migrando para as cidades porque não têm terra para trabalhar, expulsas pela expansão do latifúndio.

\section{d) $\mathbf{O}$ interesse humano.}

As notícias individuais e emotivas que despertam a compaixão:

$O$ idoso exilado que quer morrer em sua pátria, a jovem operada de um fibroma gigante, a criança heroína que salvou do fogo a sua mascote, o reencontro do marido seqüestrado, a cândida Erêndira e sua avó desalmada. (LÓPEZ VIGIL, 1997, p. 244, tradução nossa)

É o tipo de notícia que aborda a humanidade em cada um. "O interesse humano se faz presente em todos os detalhes excepcionais de uma pessoa vulgar e em todos os detalhes vulgares de uma pessoa excepcional" (MIGUEL PÉREZ CALDERÓN apud LÓPEZ VIGIL, 1997, p. 244).

\section{e) Sangue e sêmen.}

Ou, em outras palavras, como diz López Vigil, o amor e o ódio, ou Eros e Tanatos, que se traduz como sexo e violência. 
O valor-notícia no jornalismo, não importando o veículo, tem critérios de noticiabilidade que são básicos. Há quase um consenso com relação a estes critérios: o insólito, o extraordinário (GEERTS discorda deste), a proximidade, o interesse humano, a guerra, a morte, relevância, notoriedade, calamidades etc. São critérios amplos, genéricos, também aplicáveis ao radiojornalismo comunitário, mesmo considerando as peculiaridades deste veículo. Estes critérios se constituem sempre numa base para seleção do que é notícia.

Se os responsáveis pelo jornalismo na rádio comunitária sabem o que é importante para a comunidade eles podem não apenas identificar o que é notícia a partir de um ponto de vista mais geral (saiu na grande imprensa, por exemplo), como relatar fatos da comunidade, algo que, aos olhos de uma pessoa de fora, pareceria desnecessário ou distante do que se entende por jornalismo. É o caso das "notas sociais" para a rádio informar que está muito feliz porque sua filha vai se casar.

Noticiar sobre questóes familiares ou pessoais é o que Jerry de Oliveira (militante de rádios comunitárias) entende como "pessoalidade" ${ }^{\text {. A nota ou }}$ o comentário sobre determinada pessoa - uma pessoa da comunidade - será importante para todos.

Consideramos que as "notas sociais" da comunidade são um contraponto saudável às tradicionais "colunas sociais", presentes na maioria dos jornais, grandes ou pequenos. As "colunas sociais" divulgam as atividades dos poderosos e das celebridades, das elites locais e nacionais. Em contrapartida, as "notas sociais" da comunidade promovem a integraçáo e a solidariedade entre os da comunidade, revelando, muitas vezes, detalhes da intimidade dos moradores que criam laços com os demais. Quando "pequenas conquistas” individuais (formaturas, casamentos, aprovação em concurso) são tornadas públicas pela rádio elas podem aproximar os da comunidade.

\section{Comunicação}

A comunicação como o compartilhamento de objetos de consciência, presente em autores como Luiz C. Martino, Paulo Freire, Luiz Martins da Silva, Ciro Marcondes Filho, entre outros, é o cerne da comunicação comunitária. Enquanto princípio, pelo menos.

A priori, numa rádio comunitária todos da comunidade são iguais perante o microfone. Todos têm o direito de se expressar, opinar, manifestar-se. Os demais "devem" ouvi-los. Mas "os demais" incluem aquele que fala. Então os enunciadores do discurso são também os que recebem o discurso.

Antes disso, porém, antes do enunciador, do falante, há o direito ao direito de voz. Quem outorga o direito de voz? Quem dá esse direito? Na rádio comunitária são os mesmos que falam. Isto é, quem fala obteve esse direito porque fala, e não por concessão de outrem. Quem fala é também dirigente, "dono", gerente da rádio comunitária e tem esse direito. Mas quem ouve - isto é, quem é da comunidade - também tem esse triplo direito: 1) de se dar o direito de voz; 2) de falar; 3) de ser ouvinte. 
Quem fala, porém, não é somente “uma pessoa”; é também a comunidade falando por alguém - ela fala por todos. Preserva-se, portanto, a individualidade (e os direitos individuais da pessoa), mas também o coletivo. Quando uma pessoa informa na rádio que seu filho vai casar, ou quando alguém "dedica a próxima música” à namorada, ela está tratando de um fato social particular, mas, principalmente, fortalecendo valores simbólicos fortes, humanísticos, como a união entre as pessoas, a amizade, o amor, a comunhão. Por isso essas mensagens de carinho (que fazem parte da cultura do rádio, e não somente das rádios comunitárias) são tão frequentes. Todos da comunidade se sentem receptores ou desejosos de receber mensagens como esta. É um informe particular que provoca emoçôes fortes porque mexe no simbólico emotivo de cada ouvinte.

Igualmente, notícias sobre buracos nas ruas interessam a todos - ao ouvinte que mora perto ou distante dali. Ele vai querer saber como a (sua) rádio comunitária lida com o tema, como a população se organiza para resolver o problema, se o Poder Público vai agir; enfim, como vai se desenvolver o processo de denúncia-solução.

A forma de abordagem do problema tem sempre um efeito pedagógico para comunidade. Se a rádio comunitária cumpre o seu papel de guardiã da comunidade, os da comunidade estarão interessados nela. A rádio comunitária é mais que um espelho da realidade, como foi sugerido no passado para o jornalismo, ela é a comunidade e suas realidades, incluindo o imaginário, o simbólico, o transcendente, a cultura etc.

Se todos da comunidade podem falar, a rádio se torna um fórum permanente de discussóes. Nem tudo é consenso, mas, considerando a diversidade de opiniōes, culturas e visóes presentes numa comunidade, não há porque esperar um consenso sobre tudo e com todos. Como diz Dominique Wolton, nem sempre a comunicação significa comunhão, consenso - ela também pode significar conflitos. $\mathrm{Na}$ comunidade com direito de voz, também vivem os radicais, os inflexíveis, os teimosos, os intolerantes.

A comunicação comunitária pode ser um exercício permanente de democracia e de psicologia social. Porque a política não vai resolver todos os problemas da comunidade. A começar pelos dissensos internos: se A é do partido $\mathrm{X}$, e $\mathrm{B}$ pertence ao partido $\mathrm{Y}$, e se $\mathrm{X}$ e $\mathrm{Y}$ possuem posiçôes ideológicas antagônicas, A e B irão manter uma situação de beligerância no campo político. $\mathrm{O}$ consenso pode ser impossível sob o ponto de vista da política. No entanto, a paz pode acontecer quando se apela para elementos emotivos, comunitários, fraternais e similares; pode ser que A e B descubram que as diferenças ideológicas são menos importantes que as relaçooes de amizade construídas entre famílias, ou originadas na infância...

Produzir consensos não é função da comunicação comunitária. O que a comunicação comunitária possibilita é a "visibilidade da voz" para os da comunidade. Este direito ao saber (saber que pode falar) já é um saber que antecede o que se diz. É um saber e um poder. Se existe a rádio comunitária, agora (eis a dimensão temporal, histórica) o morador da comunidade pode dizer "eu posso falar". A primeira pessoa é o indivíduo, "eu”, que obteve esse direito; daí, diz, 
"posso"; o verbo é "falar", mas o que antecede é o poder. Se não tem esse poder (o acesso ao veículo e, no caso, a "propriedade" do veículo) não pode "falar" a comunidade inexiste ou é invisível. Mas, quando pode falar, a comunidade deixa de ser invisível ou excluída. Ela passa a "se ver" na rádio. E ela existe porque existe na rádio.

Tais elementos típicos da comunicação em sua forma mais ampla, e da comunicação comunitária em sua concepção restrita, configuram o radiojornalismo da emissora.

\section{Considerações Finais}

Diante do que foi exposto, podemos deduzir a existência nas rádios comunitárias de uma conceituação diferente para o radiojornalismo. Esta concepção de jornalismo é construída basicamente por um voluntariado instalado na emissora (e pelas demais intervençóes da comunidade) que toma como base o senso comum e a prática diária daquilo que seus praticantes entendem por jornalismo. Este radiojornalismo incorpora alguns informes tradicionais veiculados na imprensa, mas também o informe pessoal e familiar, valorizando principalmente a comunidade.

Quando o jornalismo é reconstruído também é reconstruído o valor-notícia. $\mathrm{O}$ valor-notícia aqui é amplo no sentido de que o sensacional, o extraordinário, o fantástico, pode ser notícia, mas não é o bastante. A morte de alguém da comunidade, eventos que promovem as autoridades, inauguração de obras públicas, não necessariamente se tornam notícia.

De um modo geral podemos considerar os valores-notícias de uma rádio comunitária submetidos a três gêneros de informes:

1. Notícia - O fato ou acontecimento nos moldes do jornalismo tradicional, com as peculiaridades estabelecidas para as RCs.

2. Serviço - Campanhas, oferta de emprego, localização de pessoa desaparecida, documentos perdidos etc.

3. Social/afetivo - Informes pessoais ou das famílias; reunióes, casamentos, batizados etc.

No que se refere à prestação de serviços à comunidade através do radiojornalismo, está claro que temos aqui uma das principais missóes da RC. Foi observado nas oito emissoras pesquisadas que a prestaçáo de serviços acontece mesmo quando não há algo que se assemelhe a um noticiário ou outra marca do radiojornalismo tradicional - mesmo quando a rádio não tem programa específico de jornalismo há pessoas (locutores) fazendo isso.

Existe uma demanda natural da comunidade em ser informada sobre quem está oferecendo empregos; há desempregados em busca de empregos; há pessoas tentando localizar documentos perdidos; a comunidade está interessada nas campanhas de Saúde, em matrículas nas escolas. Na comunidade de poucos recursos, há uma demanda por roupas e agasalhos, comida, utensílios domésticos, próteses e cadeiras de rodas, material de construção. 
A comunidade é transformada numa espécie de filtro genérico para os valores-notícias da rádio comunitária. Ela é a principal medida e fronteira para o que é notícia na rádio. Se o radiojornalismo da rádio não valoriza a noticia, se não dá espaço para o que é de interesse da comunidade, pode perder a credibilidade e, deste modo, sua razão de ser.

O radiojornalismo praticado na emissora comunitária, mesmo diferenciado dos modelos tradicionais, uma vez que construído por pessoas sem formação na área, irá refletir ou não essa relação com a comunidade. Considerando as finalidades estabelecidas pela Lei 9.612/98, podemos classificar "estar a serviço da comunidade" como um dos critérios para avaliar a qualidade da emissora. Diz o texto da Lei:

Art. $3^{\circ}$ O Serviço de Radiodifusão Comunitária tem por finalidade o atendimento à comunidade beneficiada, com vistas a:

I - dar oportunidade à difusão de ideias, elementos de cultura, tradiçóes e hábitos sociais da comunidade;

II - oferecer mecanismos à formação e integração da comunidade, estimulando o lazer, a cultura e o convivio social;

III - prestar serviços de utilidade pública, integrando-se aos serviços de defesa civil, sempre que necessário;

IV - contribuir para o aperfeiçoamento profissional nas áreas de atuaçäo dos jornalistas e radialistas, de conformidade com a legislação profissional vigente;

$V$-permitir a capacitação dos cidadãos no exercício do direito de expressão da forma mais acessivel possivel.

Se podemos supor a existência de um radiojornalismo diferenciado, o mesmo podemos conceber para os valores-notícias. Teríamos, portanto, valores-notícias singulares, específicos para as rádios comunitárias. Nossa pesquisa indica que esses valores-notícias estão sendo construídos. Não temos ainda uma configuração final. Aqui apontamos somente alguns critérios de noticiabilidade - sugerindo que, no futuro, este conjunto se tornará mais consistente e, portanto, visível. O fato de termos, neste momento, fazendo radiojornalismo nas RCs, um grupo heterogêneo de pessoas (uns poucos com formação em jornalismo e uma maioria que faz uso do senso comum) sugere a possibilidade futura de construção de uma conceituação híbrida para valores-notícias. Esta conceituação, talvez, seja única, peculiar, às rádios comunitárias.

\section{Referências bibliográficas}

CLEVES, José. A justiça dos lobos: porque a imprensa tomou o meu lugar no banco dos réus. Belo Horizonte: Biográfica, 2009.

GEERTS, Andrés. Guia para El trabajo com corresponsales populares. 
Série: como hacer rádio popular $\mathrm{n}^{\circ} 1$. Quito (Equador): Associación Latinoamericana de Educación Radiofónica (ALER), 1993.

La noticia popular. Manual de Capacitación no 4. Quito (Equador): Associación Latinoamericana de Educación Radiofónica (ALER), 1992.

LÓPEZ VIGIL, José Ignacio. Manual urgente para radialistas apasionados. Quito (Equador): Associação Mundial das Rádios Comunitárias (AMARC), 1997.

LUZ, Dioclécio. Radiojornalismo em rádios comunitárias: conceitos e práticas. 320 f. Dissertação de Mestrado. Faculdade de Comunicação, Programa de Pós-Graduação, Universidade de Brasília (UnB), Brasília, 2011.

MARCONDES FILHO, Ciro. A saga dos cães perdidos. 2 ed. São Paulo: Hackers editores, 2002.

MARTINO, Luís Mauro Sá. Mídia e poder simbólico. São Paulo: Paulus, 2003.

PARADA, Marcelo. Rádio: 24 horas de jornalismo. Sáo Paulo: Panda, 2000.

PEREIRA JUNIOR, Luiz Costa. A apuração da notícia. Petrópolis: Vozes, 2010.

TRAQUINA, Nelson. Teorias do jornalismo, a tribo jornalistica: uma comunidade interpretativa transnacional. Vol. II, Florianópolis: Insular, 2005.

\section{Notas}

1. A questáo da notabilidade, como observa o próprio Traquina mostra porque o jornalismo está mais voltado para os acontecimentos e menos para as problemáticas. Uma passeata é notícia, mas, "por não ser visível", o jornalismo opta por não tratar das condições de trabalho dos que fizeram a greve. As rádios comunitárias pesquisadas pretendem enfrentar o desafio de abordar as problemáticas da comunidade e não apenas relatar os acontecimentos.

2. Edisvânio Nascimento, dirigente e fundador da Santa Luz FM, foi um dos agraciados com o prêmio "Jornalista amigo da criança", outorgado em 2007 pela Agência de Notícias dos Direitos da Infância (Andi). Ele recebeu o prêmio pelo seu trabalho à frente de uma rádio que operava sem autorização. Por três vezes a rádio foi fechada e teve seus equipamentos aprendidos pela Anatel e pela Polícia Federal. Edisvânio é formado em Letras e, em janeiro de 2010, iniciou o curso de Comunicaçáo Social na Universidade Estadual da Bahia (Uneb). Depoimento ao autor em 24/9/2009.

3. Consideraremos "notas sociais" os informes sobre as relaçóes sociais e as conquistas pessoais e familiares dos que constituem a comunidade.

4. Jerry Oliveira coordena uma rede de rádios comunitárias de Campinas (SP), que transmitem noticiário jornalístico diário. Entrevista ao autor em 02/06/2010. 